\title{
Standardized Extract from Caesalpinia spinosa is Cytotoxic Over Cancer Stem Cells and Enhance Anticancer Activity of Doxorubicin
}

\author{
Tito A. Sandoval, ${ }^{*}$ Claudia P. Urueña, ${ }^{*}$ Mónica Llano, ${ }^{*}$ Alejandra Gómez-Cadena,* \\ John F. Hernández, ${ }^{*}$ Luis Gonzalo Sequeda ${ }^{\dagger}$ Alix E. Loaiza, ${ }^{\dagger}$ Alfonso Barreto, ${ }^{*}$ \\ Shaoping $\mathrm{Li}^{*}$ and Susana Fiorentino* \\ *Department of Microbiology \\ ${ }^{\dagger}$ Departament of Chemistry, Pontificia Universidad Javeriana \\ Grupo de Investigación Fitoquímica Universidad Javeriana (GIFUJ) \\ Bogotá, Colombia \\ Institute of Chinese Medical Sciences \\ University of Macau, Macau, P.R. China
}

Published 17 November 2016

\begin{abstract}
Cancer stem cells (CSC) are the primary cell type responsible for metastasis and relapse. ABC-transporters are integral membrane proteins involved in the translocation of substrates across membranes protecting CSC from chemotherapeutic agents. A plant extract derived from C. spinosa (P2Et) previously investigated for its antitumor activity has been shown to reduce lung and spleen metastasis in mice that have been transplanted with breast cancer cells, suggesting that P2Et has a significant activity against cancer stem cells (CSC). P2Et extract was thoroughly characterized by HPLC/MS. The cytotoxicity of P2Et extract was evaluated using a MTT assay in human and murine cell lines with different profiles of resistance, by Pgp overexpression or by enrichment in cancer stem cells. The synergistic effect of P2Et with doxorubicin was evaluated in vitro in several cell lines and in vivo in mice transplanted with TS/A cells, a highly resistant cell line and enriched in $\mathrm{CD} 44^{+} \mathrm{CD} 24^{\text {low }} /-\mathrm{CSC}$. The chromatographic fingerprint of P2Et extract revealed 13 gallotannins. We also found that P2Et extract was cytotoxic to cells regardless of their resistant phenotype. Similarly, complementary activities were observed as drug efflux reversion and
\end{abstract}

Correspondence to: Prof. Susana Fiorentino, Department of Microbiology, Pontificia Universidad Javeriana, Carrera 7 \#43-82 Edificio 50 Laboratorio 101, Bogotá, Colombia. Tel/Fax: (+57) 3208320 (ext. 4103). E-mail: susana.fiorentino@javeriana.edu.co

This is an Open Access article published by World Scientific Publishing Company. It is distributed under the terms of the Creative Commons Attribution 4.0 (CC-BY) License. Further distribution of this work is permitted, provided the original work is properly cited. 
antioxidant activity. Short-treatment with P2Et extract, revealed a synergistic effect with doxorubicin in resistant cell lines. In vivo the P2Et increases mice survival in a TS/A breast cancer model associated with augmentation of calreticulin expression. Our results suggest that P2Et treatment could be used as adjuvant along with conventional chemotherapy to treat tumors with a MDR phenotype or with high frequency of CSC.

Keywords: Gallotannins; Caesalpinia spinose; Multidrug Resistance; Synergy; P-glycoprotein.

\section{Introduction}

Over the last century, the goal of conventional medicine has been to identify or create molecules that act on single molecular targets with high efficiencies and few side effects; this concept was postulated by Ehrlich and is referred to as the "magic bullet" (Strebhardt and Ullrich, 2008). However, this reductionist approach is not effective for treating complex diseases where multiple mechanisms are responsible for development, progression and resistance (Efferth and Koch, 2011). Thus, it is not surprising that single molecules fail in controlling cancer late stages (Stensland et al., 2014). Mechanisms underlying multidrug resistance in cancer, such as P-glycoprotein (Pgp) over-expression, are triggered after single drug therapy, increasing the risk of late relapse, and unfortunately, pharmacological Pgp modulation has not been very effective and on the contrary, turned out to be highly toxic (Gottesman, 2002).

Natural products can exert antitumor activity by overcoming drug resistance (Cort and Ozben, 2015). In fact, certain compounds, such as gallic acid derivatives, reverse resistance in cancer cells (Kitagawa et al., 2005) and are thus good candidates for this specific activity.

Phytotherapy is a multi-targeted approach where multiple secondary metabolites exert an antagonistic or a synergistic effect for a final therapeutic response (Rather et al., 2013). Therefore, a complex extract with multiple molecules engaged in complementary activities could become an effective therapy for cancer. Nevertheless, using complex phytotherapeutics require chemical characterization for quality control, safety and efficacy (Li et al., 2011). In addition, assessing the relationship between the chemical components in a complex extract and the antitumor effects may allow us to understand the molecular mechanisms involved, adding strong evidence for using herbal therapy to treat cancer.

Previously, we showed that a gallotannin-rich extract obtained from pods and seeds of C. spinosa (P2Et extract), induces a loss of mitochondrial membrane potential $(\Delta \psi \mathrm{m})$, nuclei fragmentation and caspase-dependent apoptosis in vitro in several tumor cells (Castaneda et al., 2012). Interestingly, P2Et also reduces lung and spleen metastasis in the 4T1 mouse breast cancer model (Uruena et al., 2013), suggesting that it has some activity against CSC, the primary cell type responsible for tumor metastasis, drug-resistance and relapse (Adorno-Cruz et al., 2015).

In this study, we thoroughly characterized the P2Et extract using HPLC/MS and demonstrated that this group of polyphenols exhibits cytotoxic activity in lines with different profiles of resistance related to MDR pumps or CSC phenotype; also, the synergistic effect of P2Et with doxorubicin in vitro and in vivo was evaluated. 


\section{Materials and Methods}

\section{Plant Material}

Caesalpinia spinosa (Molina) Kuntze (Divi-divi or tara) pods were collected in Villa de Leyva, Boyacá, Colombia and identified by Luis Carlos Jiménez from the Colombian National Herbarium (voucher specimen number COL 523714, Colombian Environmental Ministry agreement number 0454 related to the use of genetic resources and derived products). The P2Et extract was obtained as previously described (Castaneda et al., 2012).

\section{Reverse-Phase HPLC Fingerprinting}

Chromatographic fingerprinting of P2Et was performed in a HPLC Agilent 1200 series instrument with an Agilent 1200 PDA detector $(\lambda=254 \mathrm{~nm})$ (Agilent, Wilmington, USA); the compounds were separated using an Agilent Eclipse XD8 C18 column $(4.6 \times 250 \mathrm{~mm}$, $5 \mu \mathrm{m})$. Mobile phase gradient of acetonitrile and phosphoric acid $0.1 \%$ at flux of $1 \mathrm{~mL} / \mathrm{min}$; Data acquisition and analysis were performed using Chemstation v 3.0 Software.

\section{HPLC/MS/UV Analysis}

P2Et extract was analyzed using liquid chromatography coupled to mass spectrometry and UV/VIS, an LC system Agilent 1290 series instrument with an Agilent 1290 DAD detector and an Agilent 6410 triple quadrupole detector (Agilent Technologies USA) equipped with an Agilent Zorbax SB-C18 $(4.6 \times 50 \mathrm{~mm}, 1.8 \mu \mathrm{m})$ column. The absorbance was recorded at $254 \mathrm{~nm}$, and the electrospray negative ionization gas temperature was as follows: $325^{\circ} \mathrm{C}$ gas flow: $10 \mathrm{~L} / \mathrm{min}$, capillary voltage $4000 \mathrm{~V}$, nebulizer: $35 \mathrm{psi}$; mobile phase gradient of acetonitrile and formic acid.

\section{Cell Lines}

The phenotyping of all cells was performed by flow cytometry and can be found in Table 1. MES-SA/DX5 (ATCC® CRL-1976 ${ }^{\mathrm{TM}}$ ) was used to obtain MES-SA Pgp ${ }^{+}$and $\mathrm{Pgp}^{-}$via cell sorting using a BD FACS Aria II; K562 Pgp ${ }^{+}$and $\mathrm{Pgp}^{-}$were obtained as a gift from Professor Karl Tsim (HKSTU, Hong Kong) and the lines were morphologically compared with K562 (ATCC® CCL243 ${ }^{\mathrm{TM}}$ ). Pgp expression was confirmed by labelling with Anti-Human P-glycoprotein (BD Pharmigen, 557002). 4T1 was provided by Dr. Alexzander Asea (Texas A\&M Health Science Center College of Medicine, Temple, TX) and maintained with 6-tioguanine as method of selection. Additionally, the line was tested in BALB/c mice in order to validate its tumorigenic and metastatic ability. Sub-line 4T1 side population was obtained by long-exposure of parental line with doxorubicin and followed cell sorting according to Telford (2013) and was maintained in 6-tioguanine as method of selection. Sub-line 4T1 H17 was obtained from lung metastasis after three in vivo passages according to Lelekakis (Lelekakis et al., 1999) and Pulaski and OstrandRosenberg (2001) and cultured in 6-tiogunine to guarantee its identity. TS/A line was 


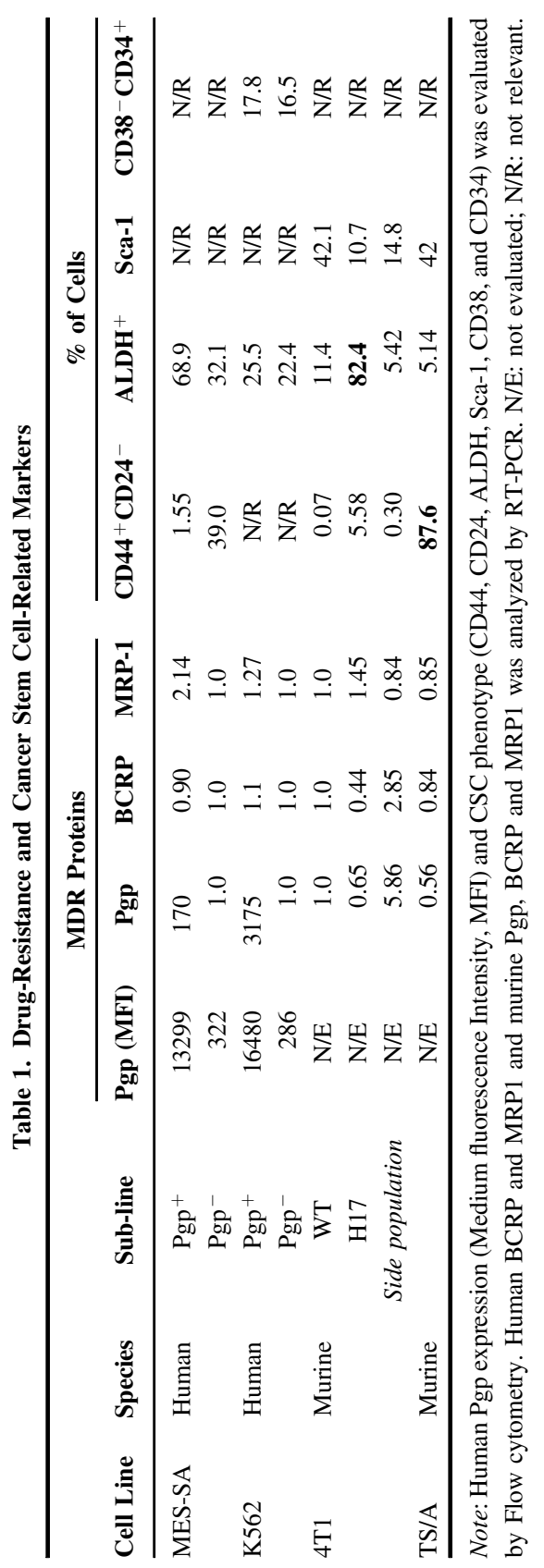


provided by Dr. Clotilde Théry (Curie Institute, Paris, France) and functionally was tested in BALB/c mice in order to validate its tumorigenic and metastatic ability. The B16 cell line was provided by professor Pedro Romero (Lausanne University, Lausanne, Switzerland). This line was tested in C57BL/6 mice in order to validate its tumorigenic and metastatic ability. The cells were tested for mycoplasma using a Myco-Probe Mycoplasma Detection Kit (R\&D Systems, Minneapolis, MN) and were maintained with ciprofloxacin $(0.5 \mu \mathrm{g} / \mathrm{mL})$.

\section{In Vitro Cytotoxicity Assays}

Cytotoxic effects were evaluated using tumor cells and methylthiazole tetrazolium (MTT) as previously described (Uruena et al., 2013). $3 \times 10^{3}$ cells/well were seeded in 96-wells plates and treated at different concentrations for $48 \mathrm{~h}$; doxorubicin was used as the positive control and ethanol or DMSO, as the negative control.

\section{Real Time and Conventional PCR}

Total RNA of cells was extracted using TRIzol LS reagent according to the manufacturer's instructions (Life technologies Corporation, Invitrogen, NY, USA). The quality and quantity of RNA were assessed with a NanoDrop spectrophotometer (NanoDrop Technologies). cDNA was synthesized with SuperScripts III Reverse Transcriptase, following the manufacturer's instructions (Invitrogen). For real-time PCR reaction $30 \mathrm{ng}$ of cDNA, DNA Master Plus SYBRGreenI (Roche Applied Science, IN, USA) and $250 \mathrm{ng}$ of forward and reverse primers in a total volume of $20 \mathrm{uL}$. Reactions were performed in two independent experiments with duplicates each one using Spectrum 48 Real Time Thermal Cyclers (ESCO). Thermal cycling conditions were: an initial denaturing step at $95^{\circ} \mathrm{C}$ for $10 \mathrm{~min}, 40$ cycles at $95^{\circ} \mathrm{C}$ for $10 \mathrm{~s}, 60^{\circ} \mathrm{C}$ for $10 \mathrm{~s}, 72^{\circ} \mathrm{C}$ for $10 \mathrm{~s}$, followed by a dissociation stage. Amplified product specificity was verified by a post-amplification melt curve analysis. The relative expression level of each transcript was normalized to the endogenous control gene GAPDH. Relative expression was calculated using the comparative method $2-\Delta \Delta \mathrm{CT}$.

\section{Flow Cytometry}

Phenotype of cancer cells were assessed by flow cytometry in a FACSAria II instrument (BD biosciences). An ALDEFLUOR assay kit (StemCell Technologies, Vancouver, BC) was used following manufacturer instructions; anti-mouse-CD44 (BD Biosciences), antimouse-CD24 (BD Biosciences), anti-mouse-Sca-1 (Ebiosciences), anti-human-CD38 (BD Biosciences), anti-human-CD34 (BD Biosciences) and anti-human-Pgp (BD Biosciences), results were analysed with FlowJo software (Tree Star Inc). To evaluate cell membrane CRT expression, cells were plated in 6-well plates and treated the following day with P2Et, Dx (positive control), alone or in combination at the $\mathrm{IC}_{50}$ concentrations or ethanol $(0,05 \%)$ for $24 \mathrm{~h}$. Cells were stained as previously described (Uruena et al., 2015). The 
mean fluorescence intensity (MFI) of stained cells was assessed within the live gate with LIVE/DEAD ${ }^{\circledR}$ Fixable Aqua Dead Cell Stain Kit (Life Technologies, Thermo scientific Eugene US).

\section{Pgp Drug-Efflux Assay}

Pgp drug-efflux activity was measured using perchlorate of tetramethylrhodamine methyl ester (TMRM) based on the report by Minderman et al. with small modifications (Minderman et al., 2002). A single cell suspension was obtained via trypsin/EDTA treatment, and $2.5 \times 10^{5}$ cells were incubated with treatments or cyclosporine A (CsA, Sigma-Aldrich, Saint Louis MO) as positive control, for $1 \mathrm{~h}$ at $4{ }^{\circ} \mathrm{C}$ and $40 \mathrm{nM}$ TMRM was then added and incubated for $1 \mathrm{~h}$ on ice. Next, the samples were incubated at $37^{\circ} \mathrm{C}$ for Pgp activation for $3 \mathrm{~h}$. After the incubation, $2 \mathrm{~mL}$ of ice-cold PBS was added, and the samples were centrifuged at $200 \times \mathrm{g}$ for $5 \mathrm{~min}$ at $4{ }^{\circ} \mathrm{C}$, washed twice with cold PBS ( $2 \%$ FCS) and analyzed in a BD FACS Aria II cytometer. The analyses were performed with viable cells selected using a LIVE/DEAD ${ }^{\circledR}$ Fixable Aqua Dead Cell Stain Kit (Life Technologies, Thermo scientific Eugene US).

\section{Synergy Effect for Drug Pre-Treatment}

Synergistic effects were determined following the report of Eid et al. (2012) with certain modifications. The cells were pre-treated with drugs at concentrations equivalent to the $\mathrm{IC}_{50}$ and $0.2 \times \mathrm{IC}_{50}$ for $3 \mathrm{~h}$. Next, the media was exchanged for fresh media with doxorubicin (Dx) at serial dilutions and the cells were incubated for $48 \mathrm{~h}$. To determine synergistic effects, viability was plotted against the Dx concentration, and the drug reduction index (DRI) and combination index (CI) were calculated for each combination as follows:

$$
D R I=\frac{I C_{50, D x}}{C_{D x, 50}} \quad C I=\frac{C_{D x, 50}}{I C_{50, D x}}+\frac{C_{P 2 E t}}{I C_{50, P 2 E t}}
$$

$\mathrm{C}_{\mathrm{Dx}, 50}$ is the $\mathrm{IC}_{50}$ of doxorubicin in combination, $\mathrm{C}_{\mathrm{P} 2 \mathrm{Et}}$ is the concentration of P2Et used in the combination experiment and $\mathrm{IC}_{50 \text {, Dx or } \mathrm{P} 2 \mathrm{Et}}$ are the $\mathrm{IC}_{50}$ for each alone.

\section{Mammosphere Culture}

Mammosphere culture was performed following he procedure of Chen et al. (2012) with modifications. In brief, $3 \times 10^{3}$ cells were seeded in a 24 -well plate with free-serum media that contains DMEM/F12 1:1(Gibco, life technologies, NY, USA), N2 supplement (Gibco, life technologies, NY, USA), B27 without vitamin A (Gibco, life technologies, NY, USA), $100 \mathrm{U} / \mathrm{mL}$ penicillin and $100 \mu \mathrm{g} / \mathrm{mL}$ streptomycin in ultra-low attachment plates (Corning, NY, USA). Next, the treatment with sub-lethal concentrations of treatments were added every day for 6 days. Finally, on the 7th day of culture, the mammospheres were collected, washed twice with PBS and centrifuged at $100 \mathrm{~g} \times 5 \mathrm{~min}$ and all the mammospheres with diameter above $50 \mu \mathrm{m}$ were counted under microscope. 


\section{In Vivo Tumor Development Experiments}

BALB/c mice were subcutaneously inoculated with $1 \times 10^{4} \mathrm{TS} / \mathrm{A}$ cells in the mammary fat pad, treatments were administered intraperitoneally (IP), mice were divided in groups as follows: Control (PBS, $n=6$ ), doxorubicin group (Dx, $1 \mathrm{mg} / \mathrm{Kg} \mathrm{IP}$, once per week, $n=6$ ), P2Et group $(18.7 \mathrm{mg} / \mathrm{Kg}$, twice per week, $n=6)$ and combined therapy group (Dx, $1 \mathrm{mg} /$ $\mathrm{Kg}$, once per week $+\mathrm{P} 2 \mathrm{Et}, 18.7 \mathrm{mg} / \mathrm{Kg}$, twice per week, $n=7$ ), tumor volume was assessed by measuring with a Vernier caliper and tumor volume was calculated as follows: $\mathrm{V}(\mathrm{mm} 3)=\left[(\text { Width })^{2} \times\right.$ Length $] / 2$.

\section{Animals}

Female BALB/c mice (6 to 12 weeks old) were purchased from Charles Rivers Laboratories International, Inc. (Boston, MA, USA) and housed in an animal research facility following the established protocols of the Ethics Committee of the Science Faculty and National and International Legislation for Live Animal Experimentation (Colombia Republic, Resolution 08430, 1993; National Academy of Sciences, 2010). Mice were housed in polyethylene cages with food and water ad libitum, a controlled temperature, and a $12 \mathrm{~h}$ light/dark cycle. Before treatment, mice were acclimated for 1 week under standard conditions. This project and the format using animals was approved by the ethics committee of the Science Faculty on May 18, 2012.

\section{Statistical Analysis}

All assays were carried out three times, unless otherwise stated. All data are expressed as the mean \pm standard deviation. The $\mathrm{IC}_{50}$ values were calculated with a three parameter non-linear regression curve (GraphPad Prism 5.0, GraphPad Software, Inc., CA, USA). A one-way analysis of variance Dunnnet's post hoc test was used to analyze the differences within a control group, mammosphere number differences with control were analyzed by Mann-Whitney test. Finally, Kaplan-meier survival analysis were analyzed in (GraphPad Prism 5.0, GraphPad Software, Inc., CA, USA) and differences between survival curves were assessed by comparison log-rank Mantel-Cox test. For all cases a $p$-value less than 0.05 was considered significant.

\section{Results}

Chromatographic Fingerprint for P2Et Extract Showing Galloylquinic Acid Separation

A HPLC/MS/UV analysis for the P2Et extract was performed. TIC, shown in Fig. 1, condenses the data of thirteen primary compounds that were identified by fragmentation analysis and based on the study performed by Clifford (Clifford et al., 2007).

Next, to perform HPLC fingerprint analysis, gallic acid and ethyl gallate were isolated, and their structures were confirmed using ${ }^{1} \mathrm{H},{ }^{13} \mathrm{C}$ NMR and mass spectra analyses 


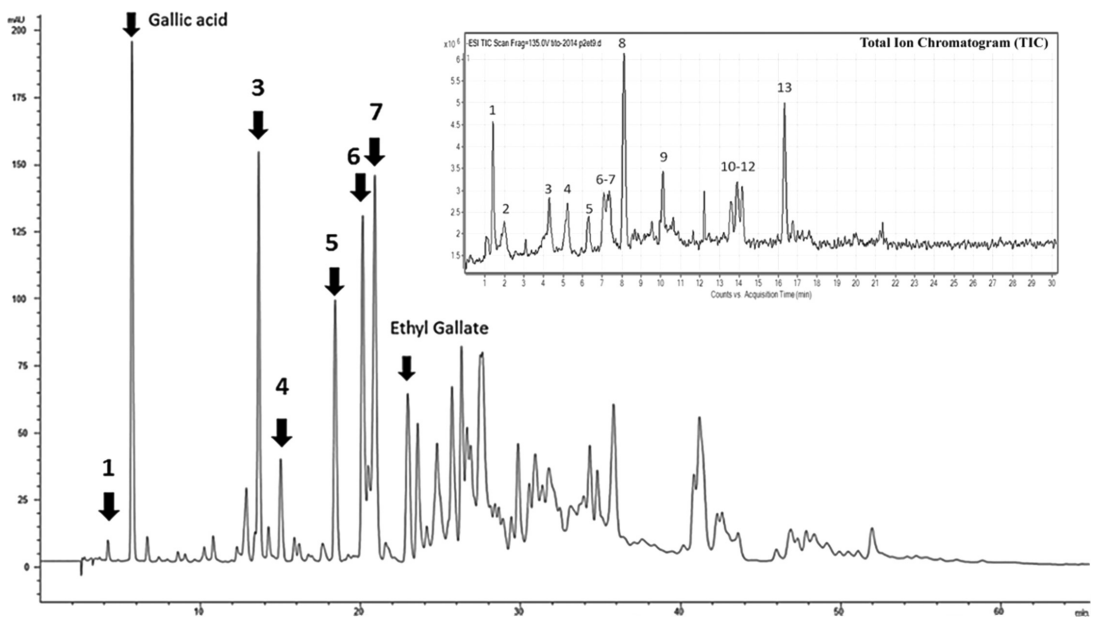

(A)

\begin{tabular}{|c|c|c|c|c|c|}
\hline Compound ID & Compound Name & $t_{R}(\min )$ & Molecular ion (m/z) & Fragment ions (m/z) & Adducts ions (m/z) \\
\hline 1 & n-O-galloylquinic acid & 1.406 & 343 & $191,169,125$ & \\
\hline 2 & gallic acid & 2.183 & 169 & 125 & \\
\hline 3 & di-O-galloylquinic acid & 4.261 & 495.1 & $342.9,168.9,130.9$ & $571\left[\mathrm{M}-2 \mathrm{H}+\mathrm{Na}^{+}\right]^{-}$ \\
\hline 4 & $\mathrm{n}$-galloylquinic acid ethyl ester & 5.223 & 371 & $343,320.7,239,169.1,130.7$ & \\
\hline 5 & tri-O-galloylquinic acid & 6.296 & 647 & $345.1,174.9,130.8$ & $668.9\left[\mathrm{M}-2 \mathrm{H}+\mathrm{Na}^{+}\right]^{-}$ \\
\hline 6 & tetra-O-galloylquinic acid & 7.073 & 799 & $647,247.1,174.8,131.0$ & $668.9\left[\mathrm{M}-2 \mathrm{H}+\mathrm{Na}^{+}\right]^{-}$ \\
\hline 7 & tri-O-galloyquinic acid & 7.354 & 647 & $494.9,334.1,247,175.1,131.1$ & $669.1\left[\mathrm{M}-2 \mathrm{H}+\mathrm{Na}^{+}\right]^{-}$ \\
\hline 8 & ethyl gallate & 8.101 & 197 & 124 & \\
\hline 9 & *unknown tetra-GCQ & 10.099 & 799.2 & $523.1,399,323,175.0,130.9$ & $544.9\left[523-2 \mathrm{H}+\mathrm{Na}^{+}\right]$ \\
\hline 10 & tri-O-galloyl quinic acid ethyl ester & 13.583 & 675 & $475.3,337.4,261.1,174.9,130.9$ & $697.2\left[\mathrm{M}-2 \mathrm{H}+\mathrm{Na}^{+}\right]^{-}$ \\
\hline 11 & $\begin{array}{l}\text { *di-O-galloyl quinic acid ethyl gallate } \\
\text { ester }\end{array}$ & 13.901 & 674.8 & $\begin{array}{c}474.9,348.9,261.0,197.0,175.2, \\
130.9\end{array}$ & \\
\hline 12 & tri-O-galloyl quinic acid ethyl ester & 14.168 & 675 & $475.3,337.4,261.1,174.9,130.9$ & $697.2\left[\mathrm{M}-2 \mathrm{H}+\mathrm{Na}^{+}\right]^{-}$ \\
\hline 13 & $\begin{array}{c}\text { *tri-O-galloyl quinic acid ethyl gallate } \\
\text { ester }\end{array}$ & 16.306 & 827 & $349.0,197.1$ & {$\left[349-2 \mathrm{H}+\mathrm{Na}^{a}\right]^{-}$} \\
\hline
\end{tabular}

(B)

Figure 1. Chromatographic fingerprinting and TIC analysis for P2Et. (A) Identified compounds in HPLC: 1) n-Ogalloylquinic acid $\left.\left(t_{R}: 4.231 \mathrm{~min}\right) ; 2\right)$ gallic acid $\left.\left(t_{R}: 5.724 \mathrm{~min}\right) ; 3\right)$ di-O-galloylquinic acid ( $\left.\left.t_{R}: 13.619\right) ; 4\right)$ galloylquinic acid ethyl ester $\left.\left(t_{R}: 15.002\right) ; 5\right)$ tri-O-galloylquinic acid ( $\left.\left.t_{R}: 18.404 \mathrm{~min}\right) ; 6\right)$ tetra-O-galloylquinic acid $\left.\left(t_{R}: 20.123 \mathrm{~min}\right) ; 7\right)$ tri-O-galloyquinic acid ( $\left.t_{R}: 20.892 \mathrm{~min}\right)$; and 8) ethyl gallate ( $\left.t_{R}: 22.947 \mathrm{~min}\right)$. (B) List of P2Et compounds identified using HPLC/MS: *Compound tentatively assigned, bold numbers indicate the base peak.

(Fig. S1); in this study, both compounds were used as quantitative markers (free gallic acid, $4.88 \%$ of total and ethyl gallate, $1.88 \%$ of total). Eight of the identified compounds were assigned to HPLC fingerprint as follows (Fig. 1): 1. n-O-galloylquinic ( $\left.\mathrm{t}_{R}: 4.231 \mathrm{~min}\right) ; 2$. gallic acid $\left(t_{R}=5.64\right) ; 3$. di-O-galloylquinic acid $\left(t_{R}: 13.619\right) ; 4$. galloylquinic acid ethyl ester $\left(t_{R}: 15.002\right)$; 5. tri-O-galloylquinic acid $\left(t_{R}: 18.404 \mathrm{~min}\right) ;$ 6. tetra-O-galloylquinic acid $\left(t_{R}: 20.123 \mathrm{~min}\right)$; 7. tri-O-galloyquinic acid $\left(t_{R}: 20.892 \mathrm{~min}\right) ; 8$. ethyl gallate $\left(t_{R}=22.70\right)$. IUPAC nomenclature is used for all identified compounds (Table S1). 
P2Et and its Isolated Compounds Exhibit Cytotoxic Activity in Resistant and Non-Resistant Cell Lines

P2Et exhibited a significant antioxidant activity $(11.76 \pm 0.58)$, similar to ethyl gallate $(11.37 \pm 0.21)$ but lower than gallic acid $(16.62 \pm 4.55)$. All the results are expressed according to the positive control TROLOX, an analog of vitamin E (Table S2). In addition, P2Et, ethyl gallate and gallic acid exhibited cytotoxic activity on human cells lines with or without a multidrug resistance phenotype: MES-SA/Dx5, K562, 4T1, TS/A cells and two sub-lines developed in our lab: 4T1 H17 cells and 4T1 side population. Flow cytometry analysis revealed high expression of Pgp in human cell lines with MDR phenotype; other pumps like BCRP and MRP1 were confirmed at level of mRNA in susceptible and resistant cells with similar expression in all cases. Now, in terms of CSC phenotype, higher rate of $\mathrm{ALDH}^{+}$cells in MES-SA/Dx5 $\mathrm{Pgp}^{+}$compared to $\mathrm{Pgp}^{-}$was observed. In contrast, no changes were observed for K562 between susceptible and resistant variants according to $\mathrm{CD} 8^{-} \mathrm{CD}^{2} 4^{+}$or $\mathrm{ALDH}^{+}$. Finally, in murine cell lines the 4T1 side population exhibited the highest expression of MDR pumps and 4T1 WT parental line and side population exhibited same rate of cells with CSC phenotype, on the contrary, a higher frequency of $\mathrm{CD} 44^{+} \mathrm{CD} 24^{-/ \text {low }}$ and $\mathrm{ALDH}^{+}$cells in the variant $4 \mathrm{~T} 1 \mathrm{H} 17$ was observed. Finally, TS/A exhibited a high frequency of CSC CD $44^{+} \mathrm{CD} 24^{-/ \text {low }}$ cells (Table 1).

Next, the resistance to doxorubicin in cell variants that overexpressed MDR pumps (MES/SA and K562 Pgp ${ }^{+}$) or those which exhibited CSC phenotype (4T1 H17 and TS/A) were confirmed ( $\mathrm{IC}_{50}$ above $1.0 \mu \mathrm{M}$, Table 2 ). Interestingly, P2Et and its compounds were cytotoxic against all cell lines, with only slight changes in the toxicity against cell variants with over-expression of MDR proteins or detoxifying enzyme ALDH. In addition, we

Table 2. Cytotoxic Activity of the P2Et Extract, Gallic Acid and Ethyl Gallate in Resistant and NonResistant Cell Lines

\begin{tabular}{lcccc}
\hline Cell Line & Ethyl Gallate & $\begin{array}{c}\text { Gallic Acid } \\
\boldsymbol{\mu g} / \mathbf{m l}\end{array}$ & $\mathbf{P 2 E t}$ & $\begin{array}{c}\text { Doxorubicin } \\
\boldsymbol{\mu g} / \mathbf{m l}(\boldsymbol{\mu M})\end{array}$ \\
\hline MES-SA/Dx5 $\left(\mathrm{Pgp}^{+}\right)$ & $33.69 \pm 8.70$ & $50.40 \pm 1.00$ & $25.86 \pm 7.90$ & $>5(>10)$ \\
MES-SA/Dx5 $\left(\mathrm{Pgp}^{-}\right)$ & $15.60 \pm 4.80$ & $79.14 \pm 7.44$ & $64.40 \pm 3.60$ & $0.209 \pm 0.03(0.36 \pm 0.05)$ \\
& & & & \\
& & & & \\
K562 MDR $\left(\mathrm{Pgp}^{+}\right)$ & $21.17 \pm 3.35$ & $68.90 \pm 7.90$ & $113.90 \pm 11.2$ & $>5(>10)$ \\
K562 WT (Pgp $\left.{ }^{-}\right)$ & $25.94 \pm 3.54$ & $61.39 \pm 7.10$ & $88.20 \pm 8.1$ & $0.232 \pm 0.08(0.40 \pm 0.13)$ \\
& & & & \\
4T1 side population & $13.4 \pm 10.0$ & $65.7 \pm 10.8$ & $56.10 \pm 1.50$ & $3.7 \pm 0.06(6.40 \pm 0.10)$ \\
4T1 H17 & $7.97 \pm 1.28$ & $112.65 \pm 2.35$ & $50.45 \pm 4.39$ & $0.753 \pm 0.08(1.30 \pm 0.13)$ \\
4T1 WT & $8.01 \pm 3.00$ & $38.57 \pm 7.40$ & $25.23 \pm 3.10$ & $0.186 \pm 0.05(0.32 \pm 0.10)$ \\
& & & & \\
TS/A & & & & \\
\hline
\end{tabular}

Note: Data are displayed as the mean $\pm \mathrm{SD}(n=3)$. 
observed that ethyl gallate was the most cytotoxic compound in almost all cases and remarkably P2Et was very effective in MES/SA-Dx5 Pgp ${ }^{+}$cells.

\section{P2Et and its Compounds Modulates Drug-Efflux Mediated by Pgp}

CsA increases TMRM accumulation from $151 \pm 15.6$ MFI in the control up to $6282 \pm 27.6$ MFI for CsA treated cells (Fig. S2); in the case of P2Et a dose-dependent effect with marginal but significant increasing in fluorescence up to $225 \pm 17.7$ MFI equivalent to $5 \%$ of the modulation obtained with CsA was observed, similarly to gallic acid that reaches up to $20 \%$ inhibition related to CsA. Conversely, ethyl gallate does not exhibit drug-efflux modulation at any concentration (Fig. 2A).

\section{P2Et Drug-Efflux Activity is Governed by Hydrophobic Compounds}

Sub-fractions of P2Et with different polarities from F1-24 (highest polarity) to F88-89 (lowest polarity) was obtained (Fig. S3). When drug-efflux modulation of this sub-fractions was evaluated, it was observed that the fractions with higher hydrophobicity have more

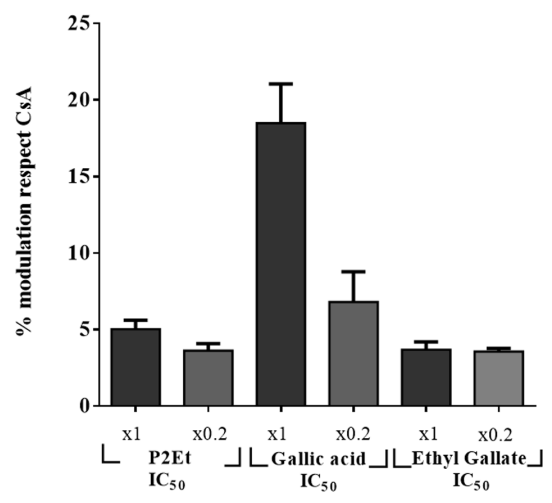

(A)

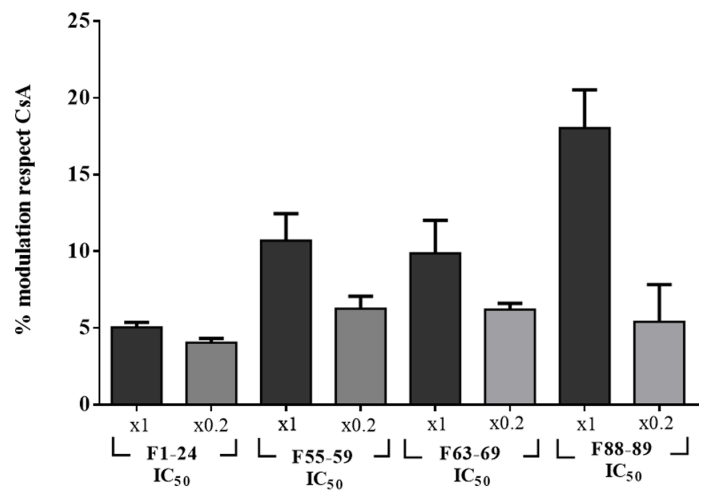

(B)

\begin{tabular}{lcccc} 
& F1-24 & F55-59 & F63-67 & F88-89 \\
\hline Hydrophobicity & Low & Medium/low & Medium/high & high \\
ABTS $(\mu \mathrm{mol}$ TROLOX/mg) & $7.02 \pm 0.14$ & $4.10 \pm 0.32$ & $4.45 \pm 0.32$ & $3.03 \pm 0.43$ \\
Cytotoxicity $\left(\mathrm{IC}_{50}, \mu \mathrm{g} / \mathrm{mL}\right)$ & $61.5 \pm 5.4$ & $63.34 \pm 6.5$ & $57.01 \pm 4.3$ & $34.28 \pm 5.6$ \\
\hline
\end{tabular}

Data are displayed as the mean $\pm \mathrm{SD}(\mathrm{n}=3)$

(C)

Figure 2. P2Et modulates the drug efflux mediated by Pgp in MES-SA/Dx5 Pgp ${ }^{+}$cell lines. (A) Representative drug efflux experiment using flow cytometry. Percentage of accumulated TMRM with respect to CsA after treatments at different concentrations $\left(\mathrm{IC}_{50}\right.$ or $\left.0.2 \times \mathrm{IC}_{50}\right)$ of $\mathrm{P} 2 \mathrm{Et}$, gallic acid and ethyl gallate. (B) Percentage of accumulated TMRM with respect to $\mathrm{CsA}$ after treatments at different concentrations $\left(\mathrm{IC}_{50}\right.$ or $\left.0.2 \times \mathrm{IC}_{50}\right)$ of subfractions of P2Et. (C) anti-oxidant and cytotoxic activity of sub-fractions of P2Et. Data are displayed as the mean $\pm \mathrm{SD}(n=3)$. 
activity on Pgp (Fig. 2B) and higher cytotoxicity (Fig. 2C). In addition, it was found that the fractions with lower hydrophobicity exhibited higher anti-oxidant activity but lower cytotoxicity (Fig. 2C); interestingly none of the sub-fractions showed the same anti-oxidant potential or cytotoxicity found with the whole P2Et, suggesting a synergistic effect.

\section{Pre-Treatment with P2Et Enhances the Cytotoxic Effect of Doxorubicin}

Short-term treatment with P2Et improves the effect of doxorubicin; synergy results can be found in Table 3 and corresponding dose-response graphics are presented in Fig. S4. The drug reduction index (DRI) and combination index (CI) were used to infer synergy, additivity or antagonism. For comparison, synergy results of gallic acid and ethyl gallate were summarized in Table S3.

We observed synergy in MES-SA/Dx5 Pgp ${ }^{+}$cells but not for Pgp ${ }^{-}$cells; in the case of K562 we could not estimate the synergistic effect in the $\mathrm{Pgp}^{+}$cells due to very high resistance to doxorubicin, however in K562 $\mathrm{Pgp}^{-}$cells we observed an antagonistic effect. On the other hand, we observed moderate synergism in 4T1 WT and 4T1 H17. In the case of TS/A we observed an additive effect. In addition, synergistic effect with the combination of gallic acid and ethyl gallate with doxorubicin (Table S3), was observed for K562 Pgp ${ }^{-}$ cells only. These results showed that P2Et could act in synergy with chemotherapeutics and improve the efficiency of the therapy.

\section{P2Et Inhibits Mammosphere Formation Ability of CSC}

To evaluate whether P2Et inhibits mammosphere formation we exposed 4T1, 4T1 H17 and TS/A to varying sub-lethal concentrations of P2Et and doxorubicin. As shown in Fig. 3, P2Et inhibited the formation of mammosphere in vitro in a dose-dependent manner in all cell

Table 3. Synergy of P2Et with Doxorubicin

\begin{tabular}{|c|c|c|c|c|c|}
\hline & & \multicolumn{2}{|c|}{ DRI } & \multirow[b]{2}{*}{ CI } & \multirow[b]{2}{*}{ Interpretation } \\
\hline \multicolumn{2}{|c|}{ Cell Line } & P2Et IC I0 $_{50}+$ Dx & P2Et $0.2 \times \mathrm{IC}_{50}+\mathrm{Dx}$ & & \\
\hline \multirow[t]{2}{*}{ MES-SA Dx5 } & $\operatorname{Pgp}^{+}$ & 6.86 & 1.87 & 0.64 & +++ \\
\hline & $\operatorname{Pgp}^{-}$ & 0.83 & 1.02 & 0.96 & \pm \\
\hline \multirow[t]{2}{*}{ K562 } & $\mathrm{Pgp}^{+}$ & $\mathrm{N} / \mathrm{C}$ & $\mathrm{N} / \mathrm{C}$ & $\mathrm{N} / \mathrm{C}$ & $\mathrm{N} / \mathrm{C}$ \\
\hline & $\operatorname{Pgp}^{-}$ & 1.28 & 0.35 & 3.09 & --- \\
\hline \multirow[t]{2}{*}{$4 \mathrm{~T} 1$} & WT & 2.22 & 1.98 & 0.65 & +++ \\
\hline & H17 & 1.86 & 1.93 & 0.72 & ++ \\
\hline \multicolumn{2}{|l|}{ TS/A } & 0.99 & 1.03 & 1.10 & \pm \\
\hline
\end{tabular}

Note: Drug reduction index (DRI) and combination index (CI) after sensitization with $\mathrm{P} 2 \mathrm{Et}$ at concentrations equivalent to $\mathrm{IC}_{50}$ and $0.2 \times \mathrm{IC}_{50}$ for $3 \mathrm{~h}$ and doxorubicin for $48 \mathrm{~h}$ in different cell lines. $\mathrm{CI}<0.1$ very strong synergism $(+++++), 0.1-0.3$ strong synergism $(++++), 0.3-0.7$ synergism $(+++), 0.7-0.85$ moderate synergism $(++), 0.85-0.9$ slight synergism $(+), 0.9-$ 1.10 nearly additivity $( \pm), 1.10-1.20$ slight antagonism $(-), 1.20-1.45$ moderate antagonism $(--), 1.45-3.3$ antagonism $(---), 3.3-10$ strong antagonism $(----)$, and $>10$ very strong antagonism (-----), N/C: not calculated. 
4T1

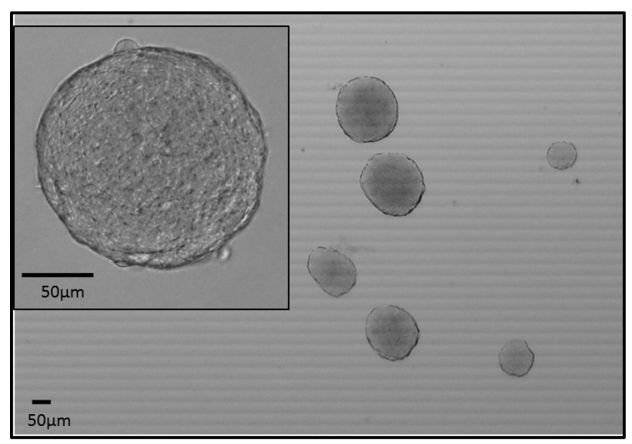

4T1 H17

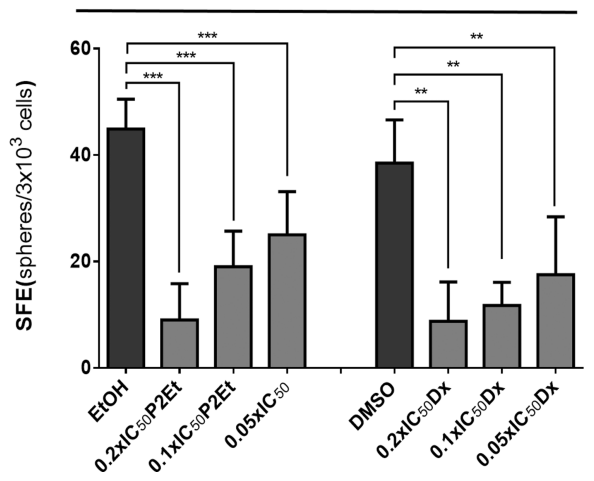

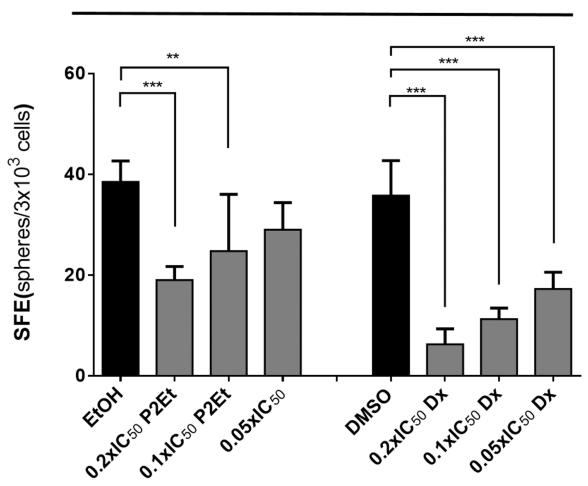

TS/A

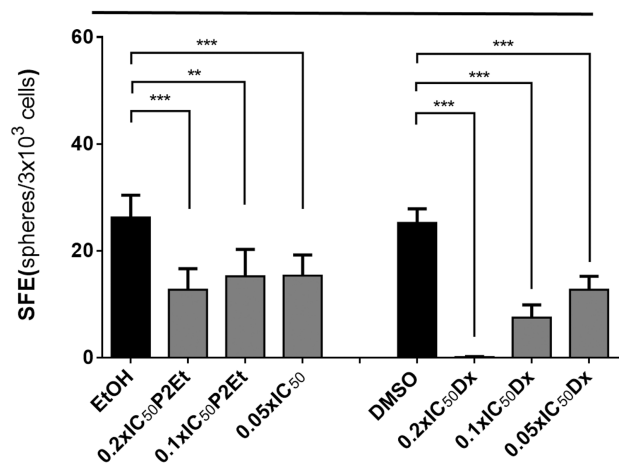

Figure 3. Inhibitory effect of P2Et inhibits Mammosphere growth under serum free and low-adherence culture conditions. Upper left: Representative mammosphere growth. 4T1, 4T1 H17 and TS/A, sphere formation efficienty (SFE) normalized to $3 \times 10^{3}$ cells after 7 days of culture. Data are displayed as the mean $\pm \operatorname{SD}(n=3)$; $* p<0.05, * * p<0.01$ and $* * * p<0.001$.

lines. In detail, for 4T1 WT we observed that the number of mammospheres declined up to $50 \%$ of control $(p>0.001)$ for cells treated with P2Et, while a reduction of $85 \%$ was observed with doxorubicin $(p>0.001)$ at the higher concentration. Likewise, in 4T1 H17 cells we observed a reduction of $80 \%(p>0.001)$ in the number of mammospheres treated with P2Et and $77 \%$ for doxorubicin, both at higher concentration. Finally, we observed a decrease in the number of mammospheres of TS/A treated with P2Et of $41 \%(p>0.001)$ and $99 \%$ with doxorubicin. Therefore, these results demonstrate that P2Et impacts CSC mammosphere formation at non-toxic concentrations, similar to that of control doxorubicin.

\section{P2Et Exhibited Synergy with Doxorubicin In Vivo and Enhance Survival of Treated Mice}

We confirmed that cytotoxicity of P2Et in TS/A cells is mediated by induction of apoptosis after 24 and $48 \mathrm{~h}$ (Fig. S4). Afterwards, we transplanted $1 \times 10^{4} \mathrm{TS} / \mathrm{A}$ cells in the 
mammary fat pad of BALB/c mice and then treated them with P2Et twice a week. We observed that P2Et treatment reduces primary tumor volume $(p<0.001)$, with significant differences since the 47th day compared to control (Fig. 4A). Similarly, there was a significant diminution in primary tumor weight $(p<0.05)$ (Fig. 4B) compared to control.

Next, we evaluated whether the combination of P2Et and doxorubicin could synergistically improve the effect of therapies in vivo. Indeed, P2Et or doxorubicin used separately significantly decreases tumor volume compared to control and improved survival, however treatment with the drug combination reduced the tumor volume and

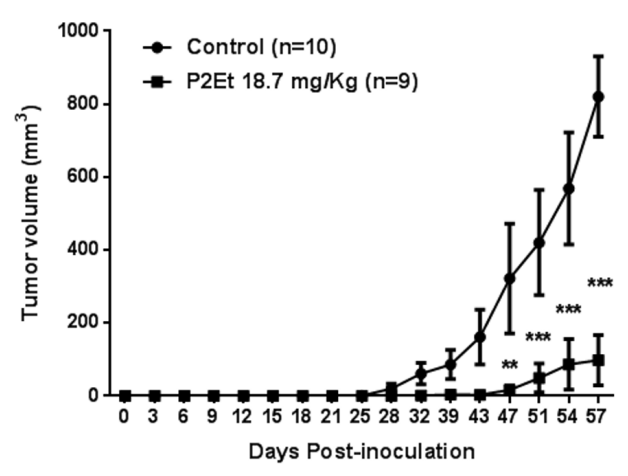

(A)

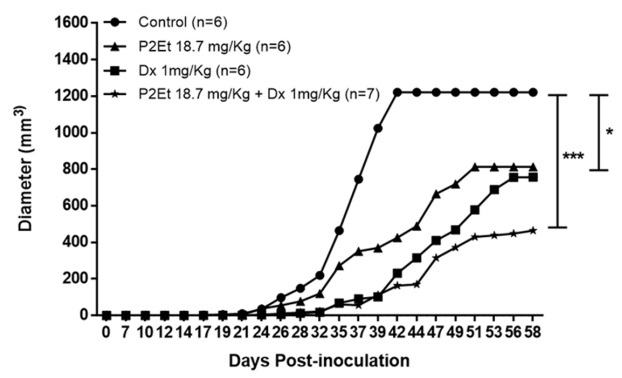

(C)

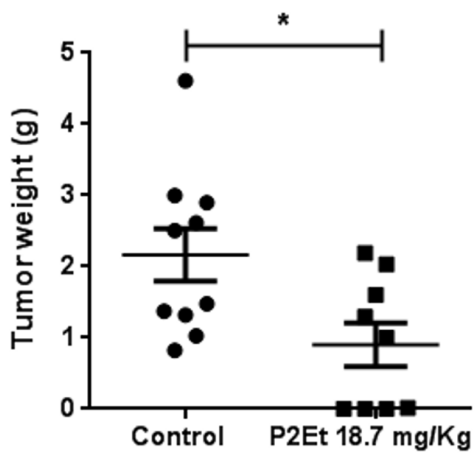

(B)

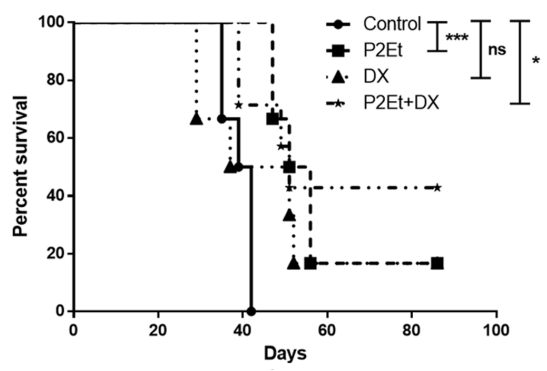

(D)

Figure 4. P2Et enhance the survival of treated mice in the TS/A model. (A) Tumor growth is decreased by treatment with P2Et extract. BALB/c mice were subcutaneously inoculated with $1 \times 10^{4} \mathrm{TS} / \mathrm{A}$ cells. Mice were divided in two groups: control group mice treated with PBS $(n=10$, black circle) and P2Et group $(n=9$, black square) treated twice by week $(18.7 \mathrm{mg} / \mathrm{Kg}$, I.P). tumor volume was measured three times each week. Results are expressed as the mean value $\left(\mathrm{mm}^{3}\right) \pm$ ESM. (B) mice were euthanized at end-point criteria and primary tumors were surgically removed and weighed. Results are expressed as mean $(\mathrm{g}) \pm \mathrm{SD}$. (C) BALB/c mice were subcutaneously inoculated with TS/A cells. Control group (PBS, circle), doxorubicin group (Dx, $1 \mathrm{mg} / \mathrm{Kg} \mathrm{IP}$ ) once each week (triangle), P2Et group (18.7 mg/Kg IP) twice a week and combined therapy group Dx (1 mg/Kg IP) + P2Et $(18.7 \mathrm{mg} / \mathrm{Kg} \mathrm{IP})$ doxorubicin once and P2Et twice per week. Tumor growth development measure as diameter $\left(\mathrm{mm}^{3}\right)$. (D) Kaplan-Meier Survival analysis. $* * * p<0.001, * * p<0.01, * p<0.05$, ns: non-significant, comparison log-rank Mantel-Cox test. E. TS/A and B16 Surface exposure of CRT determined by flow cytometry, comparisons between negative controls (Dashed line - Black), positive control Dx, P2Et treated, P2Et and Dx treated cells and the isotype control (solid histogram) are shown. MFI is also shown in brackets. 
TS/A

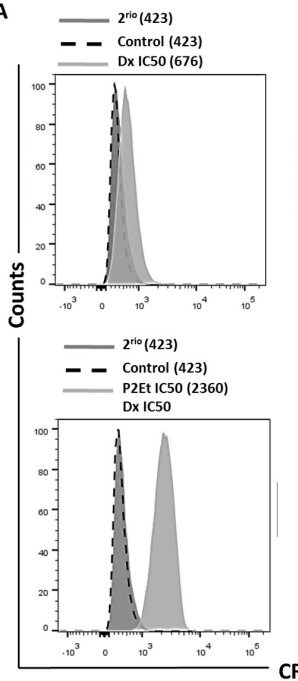

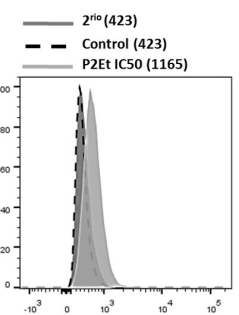

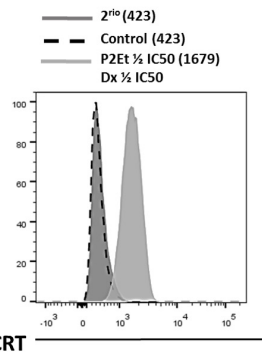

B16
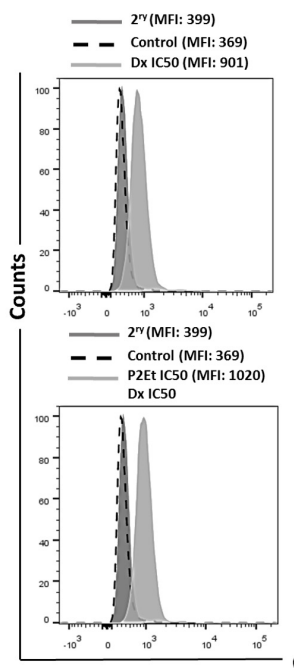

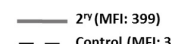

\begin{tabular}{c} 
Control (MFI: 369$)$ \\
P2Et IC50 (MFI: 625) \\
\hline
\end{tabular}

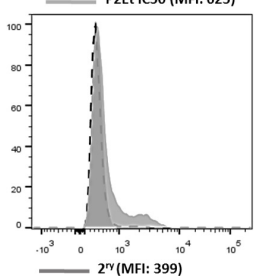

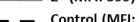
P2Et $1 / 2$ IC50 (MFI: 749) Dx $1 / 2$ IC50

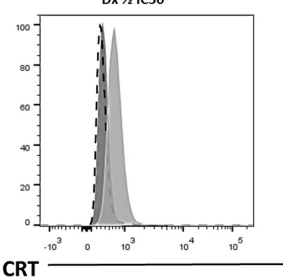

(E)

Figure 4. (Continued)

synergistically increased the antitumor effect of each one (Figs. 4C and 4D). Remarkably, the group treated with the combination of P2Et and doxorubicin exhibited an overall survival of $40 \%$ with significant differences with the control group $(p<0.05)$. Since no synergistic activity was evidenced in vitro, we asked whether synergism could be related to immune system activation in vivo, as we have previously shown (Gomez-Cadena et al., 2016; Uruena et al., 2015). In this regard, calreticulin expression at the cell membrane is considered a danger signal, and an "eat me" signal that activates dendritic cells. As expected, P2Et largely induce calreticuline expression, but surprisingly, both on TSA and B16 cells (Fig. 4E), co-treatment with P2Et and Dx at the same time significantly increasing calreticulin membrane expression (Fig. 4E).

\section{Discussion}

In the present study we did a comprehensive chemical characterization of the P2Et extract obtained from Caesalpinia spinosa in order to understand the molecular mechanisms involved in the anti-metastatic activity. The compounds present in P2Et extract show antioxidant activity, and are cytotoxic to tumor cells lines, whether they have a cancer stem cell phenotype or expression of the drug resistance pump Pgp. A significant synergistic activity with doxorubicin was observed after treating mice that were transplanted with doxorubicin resistant breast cancer cells (TSA). P2Et extract synergistic activity with doxorubicin seems to be related to the induction of calreticulin expression on the plasma membrane of tumor cells. 
C. spinosa pods are considered the second most abundant vegetal source of polyphenols, containing 55.1 GAE/100 g, compared to Galla chinensis, which contain 61.6 GAE/100 g (Chambi et al., 2013), and seemed to be the most important source until now. In the present study, we identified ten galloylquinic acids, as previously described by Clifford (Clifford et al., 2007) who studied the composition of tara tannin using HPLC$\mathrm{MS}^{n}$. He identified seven compounds from two primary families (galloylquinic acids and di-galloylquinic acids) and tentatively assigned tri-galloylquinic acids and galloyl-digalloylquinic acids. We also tentatively assigned two possible compounds that were not described previously but their structures need be verified after purification; finally, some galloylquinic common fragments suggest the presence of a tetra-galloylquinic acid. To ensure the safety and efficacy of traditional medicines and natural products is necessary implement strict quality control and regulation (Li et al., 2011). HPLC fingerprinting techniques have been used for the quality control of many components in plant-based medicines and have become mandatory for many traditional medicines (Yang et al., 2011), together with qualitative and quantitative analyses of markers (Li et al., 2011). In this study, we purified gallic acid and ethyl gallate as quantitative markers and other identified compounds as qualitative markers for future quality control of P2Et.

The MDR phenotype it is a barrier for chemotherapy success in cancer (Wind and Holen, 2011), and many efforts in overcoming drug-resistance have attempted to design specific inhibitors of MDR pumps (Cort and Ozben, 2015). However, this approach has not been as successful as expected (Moitra et al., 2011). Multicomponent traditional medicines are ideal to overcome drug resistance, because they affect multiple biological targets simultaneously (Efferth et al., 2007) and in most cases are less toxic than chemotherapeutics (Wargovich et al., 2001). Our results showed that P2Et was effective in almost all cell lines including those cells exhibiting drug resistance mechanisms, and additionally we observed that the most hydrophobic fractions exert the better drug efflux activity, which is correlated with previous reports and our self-results, where gallic acid, one of the most hydrophilic compound present in P2Et does not affect the drug efflux mediated by Pgp (Kitagawa et al., 2005) at low concentrations, but decreases Pgp mRNA expression (Chieli et al., 2010). Additionally, for alkyl gallates, studies have reported that aliphatic chains with more than eight carbons in length can overcome drug efflux mediated by Pgp (Kitagawa et al., 2005); consistent with these results, we observed here that ethyl gallate was not shown to affect drug efflux.

It is possible that some compounds present in P2Et are not targets of the pump, or that a collateral sensitivity phenomenon, principally observed in $\mathrm{Pgp}^{+}$cells, is happening as it has been previously observed (Pluchino et al., 2012). Otherwise, is possible that a particular pattern of Pgp glycosylation in these cells (Greer and Ivey, 2007) together with the changes in cell membrane composition (Clay and Sharom, 2013) could sensitize the cells to different compounds present in P2Et, having antioxidant potential, as previously observed (Chambi et al., 2013). Here, we found a very high anti-oxidant potential for P2Et, which is not due to free gallic acid because of its low concentration in the extract $(4.88 \%)$. These results suggest that in this extract, hydrophobic compounds should contribute with 
high cytotoxicity and drug efflux reversion and hydrophilic compounds contribute with anti-oxidant activity.

Some of the tumor cell lines exhibited ALDH, which defines a CSC population and plays an important role in drug resistance to cyclophosphamide and anthracyclines by scavenging aldehyde intermediaries, ROS and usually is concomitant with overexpression of multidrug resistance pumps (Cojoc et al., 2015; Mizuno et al., 2015). As expected, gallic acid, which induces ROS in spite of its antioxidant activity (Yen et al., 2002), was not cytotoxic against $\mathrm{ALDH}^{+}$cells, however P2Et does. These facts allow us to hypothesize that P2Et may be cytotoxic by mechanisms other than ROS induction. Finally, it has been reported that $\mathrm{CSC}$ with phenotype $\mathrm{CD} 44^{+} \mathrm{CD} 24^{-}$exhibited different mechanism of drug-resistance (Charafe-Jauffret et al., 2009). In this regard, P2Et was also cytotoxic against TS/A cells, which also exhibited high resistance to doxorubicin. P2Et impairs sphere formation commonly attributed to highly metastatic CSC (Uruena et al., 2013).

P2Et induces immunogenic cell death in the 4T1 breast cancer model (Uruena et al., 2015) and also B16 melanoma cells (Gomez-Cadena et al., 2016). In this work we observed that, in spite of a non-pharmacological synergy in vitro between P2Et and doxorubicin in the TS/A model, we identified a better expression of the danger signal calreticulin on the cell membrane, suggesting that a better immunogenicity of tumor cells might be implicated in the in vivo response after combined treatment (Nanni et al., 1983). It will be necessary to evaluate if the immune system is playing a role in tumor control in this model. However, our previous results highly suggest that not only a direct antitumor activity is necessary to diminish tumor progression but also well-chosen drug combinations, as those present in phytomedicines is better than a single drug (Wagner, 2011).

In conclusion, P2Et treatment could be used as adjuvant therapy together with conventional chemotherapy in tumors with a MDR phenotype or with high frequency of CSC.

\section{Acknowledgments}

Funding was provided by Departamento Administrativo de Ciencia, Tecnología e Innovación COLCIENCIAS (12011050101103) and Vicerrectoria de Investigaciones, Pontificia Universidad Javeriana (12081050401200) Bogotá, Colombia. The authors would like to thank Pontificia Universidad Javeriana for its support and the Colombian Environmental Ministry for allowing the use of genetic resources and derived products (agreement number 0454 of 15/05/2013) and Departamento Administrativo de Ciencia, Tecnología e Innovación COLCIENCIAS for the $\mathrm{PhD}$ scholarship granted to T. Sandoval. The authors would also like to thank Dr. Karl Tsim for his support in his lab at HKUST during the chemical analyses used in this study.

\section{References}

Adorno-Cruz, V., G. Kibria, X. Liu, M. Doherty, D. J. Junk, D. Guan, C. Hubert, M. Venere, E. Mulkearns-Hubert, M. Sinyuk, A. Alvarado, A. I. Caplan, J. Rich, S. L. Gerson, J. Lathia and 
H. Liu. Cancer stem cells: Targeting the roots of cancer, seeds of metastasis, and sources of therapy resistance. Cancer Res. 75: 924-929, 2015.

Castaneda, D., L. Pombo, C. Uruena, J. Hernandez and S. Fiorentino. A gallotannin-rich fraction from Caesalpinia spinosa (Molina) Kuntze displays cytotoxic activity and raises sensitivity to doxorubicin in a leukemia cell line. BMC Complement. Altern. Med. 12: 38, 2012.

Chambi, F., R. Chirinos, R. Pedreschi, I. Betalleluz-Pallardel, F. Debaste and D. Campos. Antioxidant potential of hydrolyzed polyphenolic extracts from tara Caesalpinia spinosa pods. Ind. Crops. Prod. 47: 168-175, 2013.

Charafe-Jauffret, E., C. Ginestier and D. Birnbaum. Breast cancer stem cells: Tools and models to rely on. BMC Cancer 9: 202, 2009.

Chen, D., S. Pamu, Q. Cui, T. H. Chan and Q. P. Dou. Novel epigallocatechin gallate (EGCG) analogs activate AMP-activated protein kinase pathway and target cancer stem cells. Bioorg. Med. Chem. 20: 3031-3037, 2012.

Chieli, E., N. Romiti, I. Rodeiro and G. Garrido. In vitro modulation of ABCB1/P-glycoprotein expression by polyphenols from Mangifera indica. Chem. Biol. Interact. 186: 287-294, 2010.

Chou, T.C. Theoretical basis, experimental design, and computerized simulation of synergism and antagonism in drug combination studies. Pharmacol. Rev. 58: 621-681, 2006.

Clay, A.T. and F.J. Sharom. Lipid bilayer properties control membrane partitioning, binding, and transport of p-glycoprotein substrates. Biochemistry 52: 343-354, 2013.

Clifford, M.N., S. Stoupi and N. Kuhnert. Profiling and characterization by LC-MSn of the galloylquinic acids of green tea, tara tannin, and tannic acid. J. Agric. Food Chem. 55: 27972807, 2007.

Cojoc, M., K. Mabert, M.H. Muders and A. Dubrovska. A role for cancer stem cells in therapy resistance: Cellular and molecular mechanisms. Semin. Cancer Biol. 31: 16-27, 2015.

Cort, A. and T. Ozben. Natural product modulators to overcome multidrug resistance in cancer. Nutr. Cancer 2016: 1-13, 2015.

Efferth, T. and E. Koch. Complex interactions between phytochemicals. The multi-target therapeutic concept of phytotherapy. Curr. Drug Targets 12: 122-132, 2011.

Efferth, T., P.C. Li, V.S. Konkimalla and B. Kaina. From traditional Chinese medicine to rational cancer therapy. Trends Mol. Med. 13: 353-361, 2007.

Eid, S.Y., M.Z. El-Readi and M. Wink. Synergism of three-drug combinations of sanguinarine and other plant secondary metabolites with digitonin and doxorubicin in multi-drug resistant cancer cells. Phytomedicine 19: 1288-1297, 2012.

Gomez-Cadena, A., C. Urueña, K. Prieto, A. Martinez-Usatorre, A. Donda, A. Barreto, P. Romero and S. Fiorentino. Immune-system-dependent anti-tumor activity of a plant-derived polyphenol rich fraction in a melanoma mouse model. Cell Death Dis. 7: 134-145, 2016.

Gottesman, M.M. Mechanisms of cancer drug resistance. Annu. Rev. Med. 53: 615-627, 2002.

Greer, D.A. and S. Ivey. Distinct N-glycan glycosylation of P-glycoprotein isolated from the human uterine sarcoma cell line MES-SA/Dx5. Biochim. Biophys. Acta. 1770: 1275-1282, 2007.

Kitagawa, S., T. Nabekura, S. Kamiyama, T. Takahashi, Y. Nakamura, Y. Kashiwada and Y. Ikeshiro. Effects of alkyl gallates on P-glycoprotein function. Biochem. Pharmacol. 70: 12621266, 2005.

Lelekakis, M., J. Moseley, T.J. Martin, D. Hards, E. Williams, P. Ho, D. Lowen, J. Javni, F. Miller, J. Slavin and R. Anderson. A novel orthotopic model of breast cancer metastasis to bone. Clin. Exp. Metastasis 17: 163-170, 1999.

Li, S., J. Zhao and B. Yang. Strategies for quality control of Chinese medicines. J. Pharm. Biomed. Anal. 55: 802-809, 2011.

Minderman, H., A. Suvannasankha, K.L. O'Loughlin, G.L. Scheffer, R.J. Scheper, R.W. Robey and M.R. Baer. Flow cytometric analysis of breast cancer resistance protein expression and function. Cytometry 48: 59-65, 2002. 
Mizuno, T., N. Suzuki, H. Makino, T. Furui, E. Morii, H. Aoki, T. Kunisada, M. Yano, S. Kuji, Y. Hirashima, A. Arakawa, S. Nishio, K. Ushijima, K. Ito, Y. Itani and K. Morishige. Cancer stem-like cells of ovarian clear cell carcinoma are enriched in the ALDH-high population associated with an accelerated scavenging system in reactive oxygen species. Gynecol. Oncol. 137: 299-305, 2015.

Moitra, K., H. Lou and M. Dean. Multidrug efflux pumps and cancer stem cells: Insights into multidrug resistance and therapeutic development. Clin. Pharmacol. Ther. 89: 491-502, 2011.

Nanni, P., C. de Giovanni, P.L. Lollini, G. Nicoletti and G. Prodi. TS/A: A new metastasizing cell line from a BALB/c spontaneous mammary adenocarcinoma. Clin. Exp. Metastasis 1: 373$380,1983$.

Pluchino, K.M., M.D. Hall, A.S. Goldsborough, R. Callaghan and M.M. Gottesman. Collateral sensitivity as a strategy against cancer multidrug resistance. Drug Resist. Updat. 15: 98-105, 2012.

Pulaski, B.A. and S. Ostrand-Rosenberg. Mouse 4T1 breast tumor model. Curr. Protoc. Immunol. John Wiley \& Sons, Inc. 2001.

Rather, M.A., B.A. Bhat and M.A. Qurishi. Multicomponent phytotherapeutic approach gaining momentum: Is the "one drug to fit all" model breaking down? Phytomedicine 21: 1-14, 2013.

Stensland, K.D., R.B. McBride, A. Latif, J. Wisnivesky, R. Hendricks, N. Roper, P. Boffetta, S.J. Hall, W.K. Oh and M.D. Galsky. Adult cancer clinical trials that fail to complete: An epidemic? J. Natl. Cancer Inst. 106: 2014.

Strebhardt, K. and A. Ullrich. Paul Ehrlich's magic bullet concept: 100 years of progress. Nat. Rev. Cancer 8: 473-480, 2008.

Telford, W.G. Stem cell identification by DyeCycle Violet side population analysis. Methods Mol. Biol. 946: 163-179, 2013.

Uruena, C., A. Gomez, T. Sandoval, J. Hernandez, S. Li, A. Barreto and S. Fiorentino. Multifunctional $\mathrm{T}$ lymphocytes generated after therapy with an antitumor gallotanin-rich normalized fraction are related to primary tumor size reduction in a breast cancer model. Integr. Cancer Ther. 14: 468-483, 2015.

Uruena, C., J. Mancipe, J. Hernandez, D. Castaneda, L. Pombo, A. Gomez, A. Asea and S. Fiorentino. Gallotannin-rich Caesalpinia spinosa fraction decreases the primary tumor and factors associated with poor prognosis in a murine breast cancer model. BMC Complement. Altern. Med. 13: 74, 2013.

Wagner, H. Synergy research: Approaching a new generation of phytopharmaceuticals. Fitoterapia 82: 34-37, 2011.

Wargovich, M.J., C. Woods, D.M. Hollis and M.E. Zander. Herbals, cancer prevention and health. J. Nutr. 131: 3034S-3036S, 2001.

Wind, N. and I. Holen. Multidrug Resistance in breast cancer: From in vitro models to clinical studies. Int. J. Breast Cancer 2011: 2011-2023, 2011.

Yang, D.-Z., Y.-Q. An, X.-L. Jiang, D.-Q. Tang, Y.-Y. Gao, H.-T. Zhao and X.-W. Wu. Development of a novel method combining HPLC fingerprint and multi-ingredients quantitative analysis for quality evaluation of traditional chinese medicine preparation. Talanta 85: 885890, 2011.

Yen, G.-C., P.-D. Duh and H.-L. Tsai. Antioxidant and pro-oxidant properties of ascorbic acid and gallic acid. Food Chem. 79: 307-313, 2002. 


\section{Supplementary Materials}

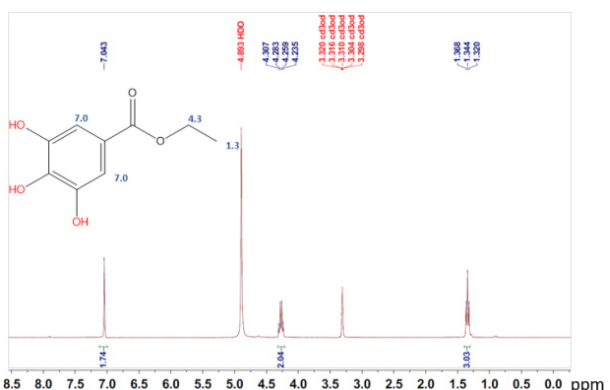

(A)

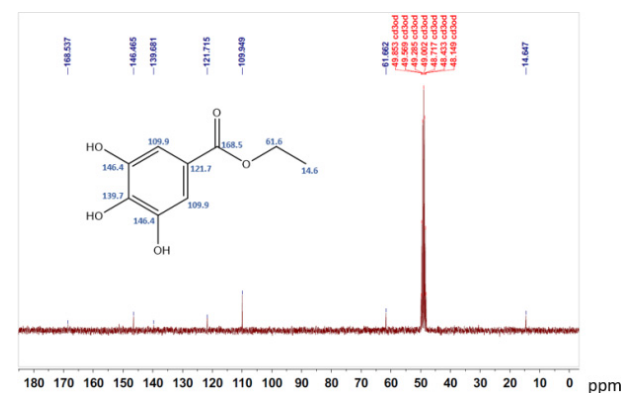

(B)

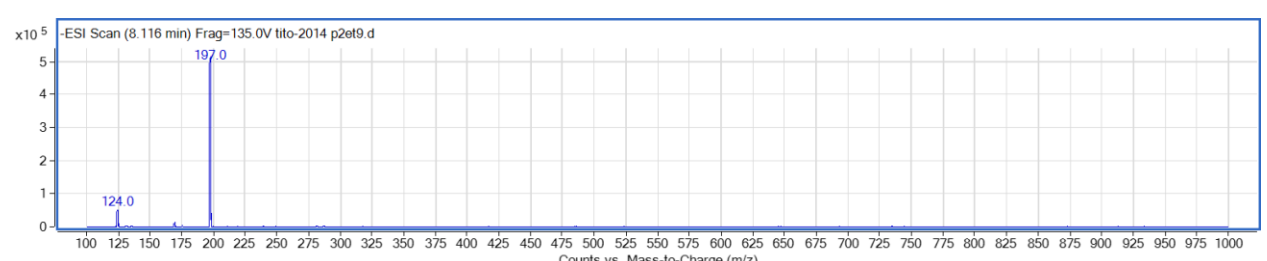

(C)

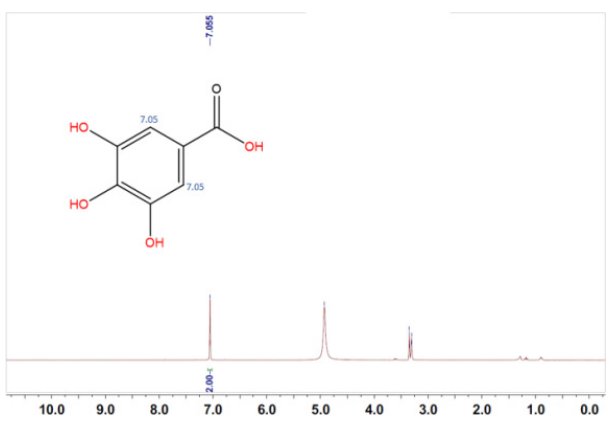

(D)

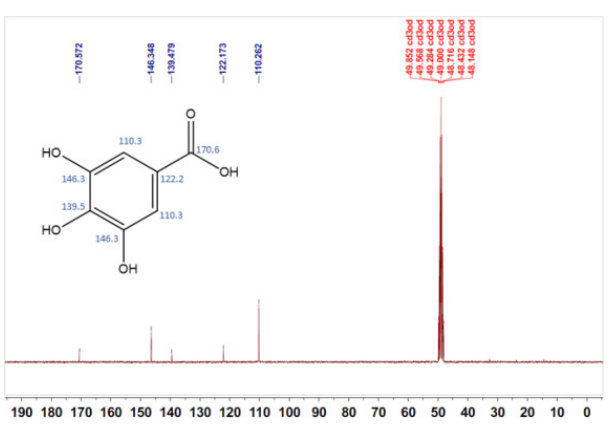

(E)

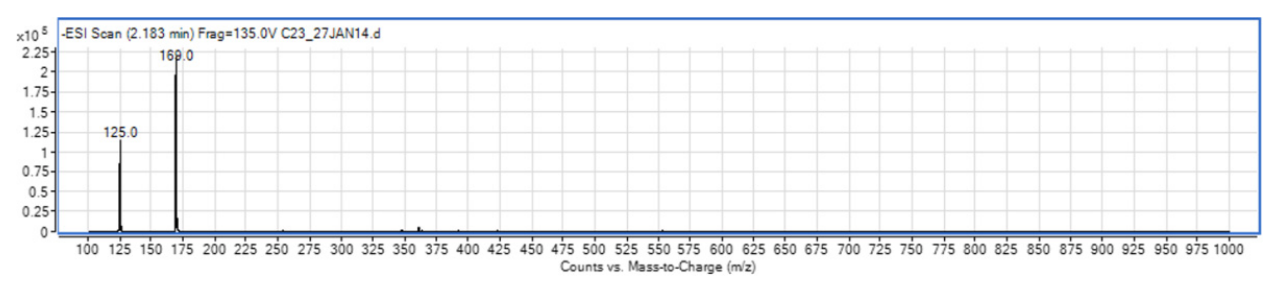

(F)

Figure S1. ${ }^{1} \mathrm{H}$ and ${ }^{13} \mathrm{C}$ NMR and MS spectra for purified: A-C Gallic acid; D-F Ethyl gallate. 


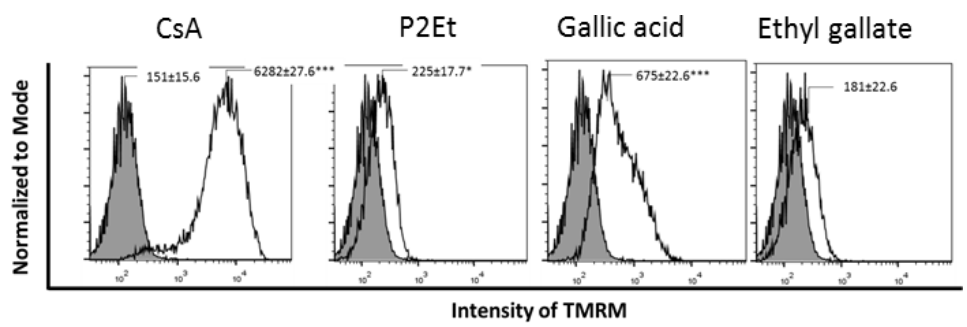

(A)

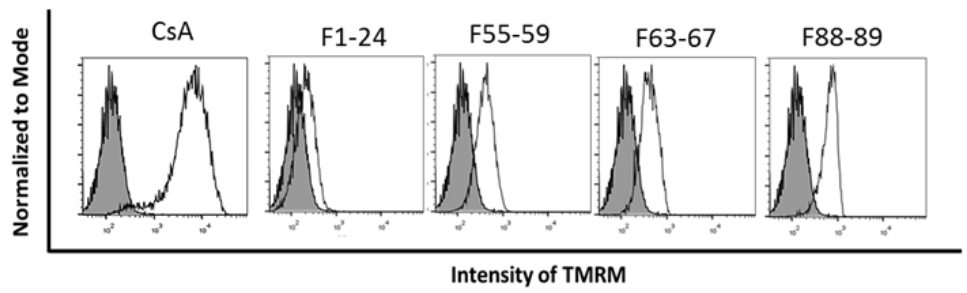

(B)

Figure S2. P2Et modulates drug efflux mediated by Pgp in MES-SA/Dx5 Pgp ${ }^{+}$cell lines (A) representative drug efflux experiment using flow cytometry in MES-SA-DX5 Pgp ${ }^{+}$cells through co-incubating TMRM with concentrations of treatment equivalent to $\mathrm{IC}_{50}$. Filled-grey: vehicle; solid line: cyclosporine A $5 \mu \mathrm{M}, \mathrm{P} 2 \mathrm{Et} 25.8 \mu \mathrm{g} / \mathrm{ml}$, gallic acid $50.4 \mu \mathrm{g} / \mathrm{ml}$ and ethyl gallate $33.69 \mu \mathrm{g} / \mathrm{ml}$. (B) representative drug efflux experiment using flow cytometry in MES-SA-DX5 Pgp ${ }^{+}$cells by co-incubating TMRM with concentrations of treatment equivalent to $\mathrm{IC}_{50}$ of sub-fractions of P2Et.

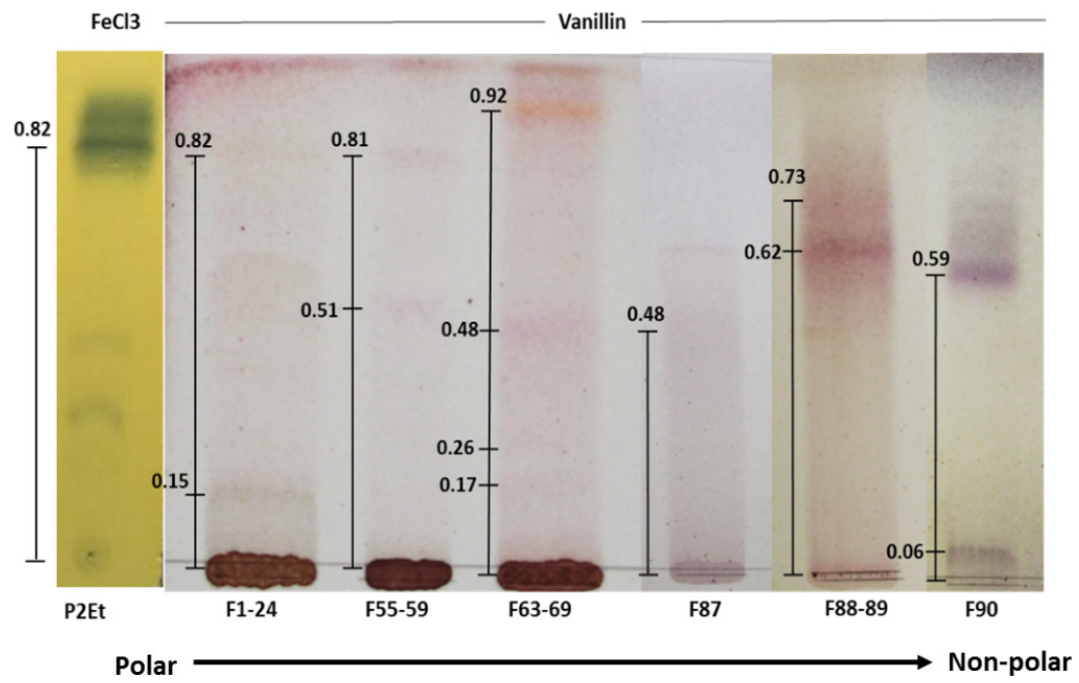

Figure S3. TLC profile sub-fractions obtained from P2Et fraction. Retention factor (RF) of bands obtained by TLC, flavonoids and triterpenoids evidenced by vanillin reagent and tannins by $\mathrm{FeCl}_{3}$ reagent. The total phenols in $\mathrm{P} 2 \mathrm{Et}$ were estimated using the Folin-Ciocalteu colorimetric method. Results are expressed as grams of gallic acid equivalent (GAE) per $100 \mathrm{~g}$ of dry extract, and the phenolic compounds in the P2Et extract were $94.47 \pm 4.23 \mathrm{~g} \mathrm{GAE} / 100 \mathrm{~g}$. 

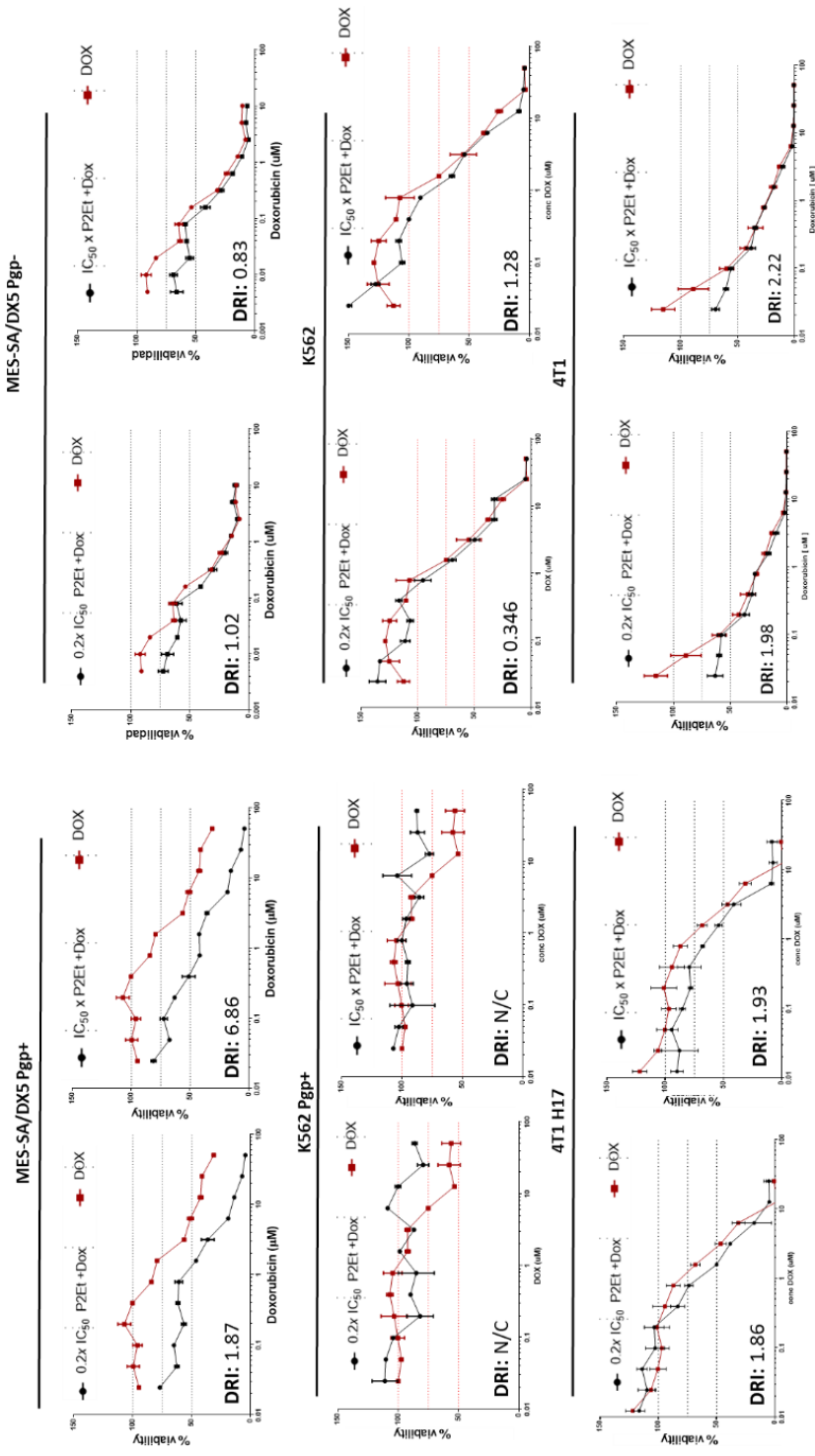

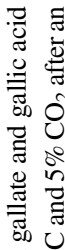

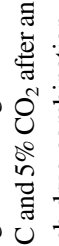

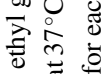

苞

ख

究要

穿

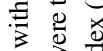

更

它

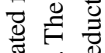

ฮ

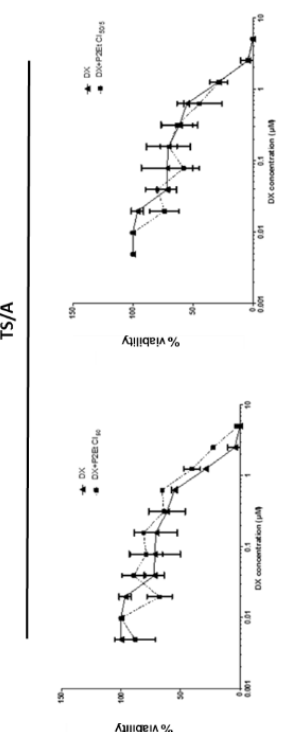

这递

过

告

ठ

के

过

可

进

娄

틀 웅

एँ

क

在

苛

券

品

웡

응

产

氙

武

ฮี

绕

ำ

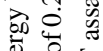

空言曷

施

क

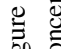




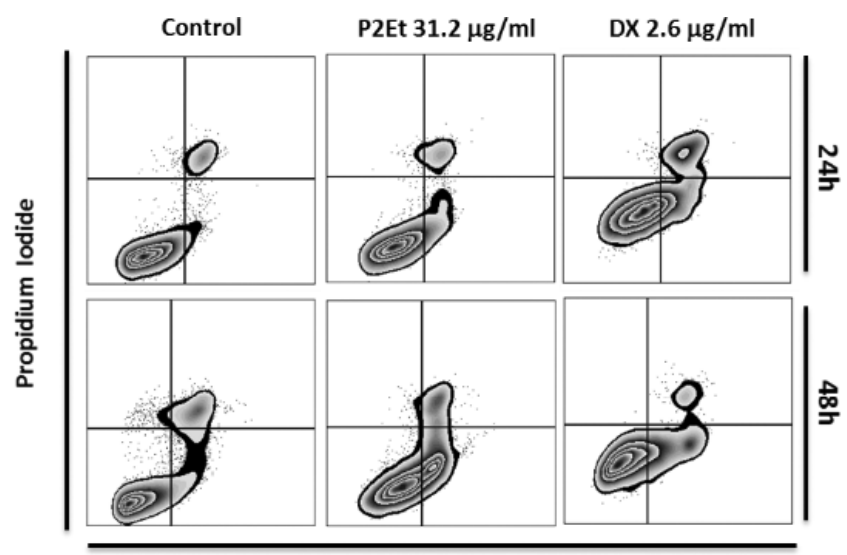

Annexin V-Alexa Fluor 488

(A)

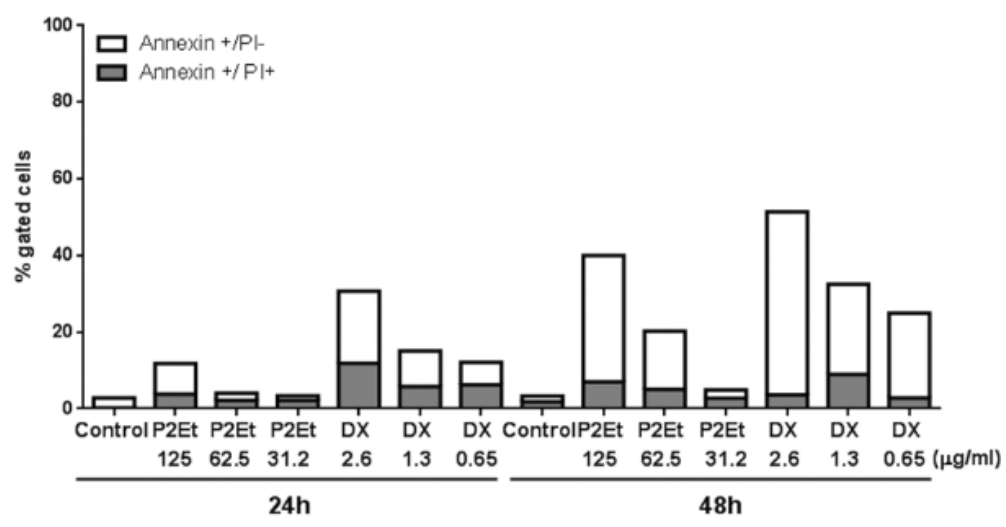

(B)

Figure S5. Phosphatidil serine externalization in TS/A cells, induced by P2Et fraction treatment. Phosphatidylserine externalization in TS/A cells by flow cytometry after treatment for $24 \mathrm{~h}$ and $48 \mathrm{~h}$ with P2Et fraction, doxorubicin (DX, positive control), or ethanol (negative control). The top panel is a representative dot plot showing the treatments; bottom is a representative histogram showing percent (\%) PS/PI cells after 24 and $48 \mathrm{~h}$ of treatment. Results were analyzed with FlowJo software (Tree Star Inc) and the experiments were performed in triplicate. 


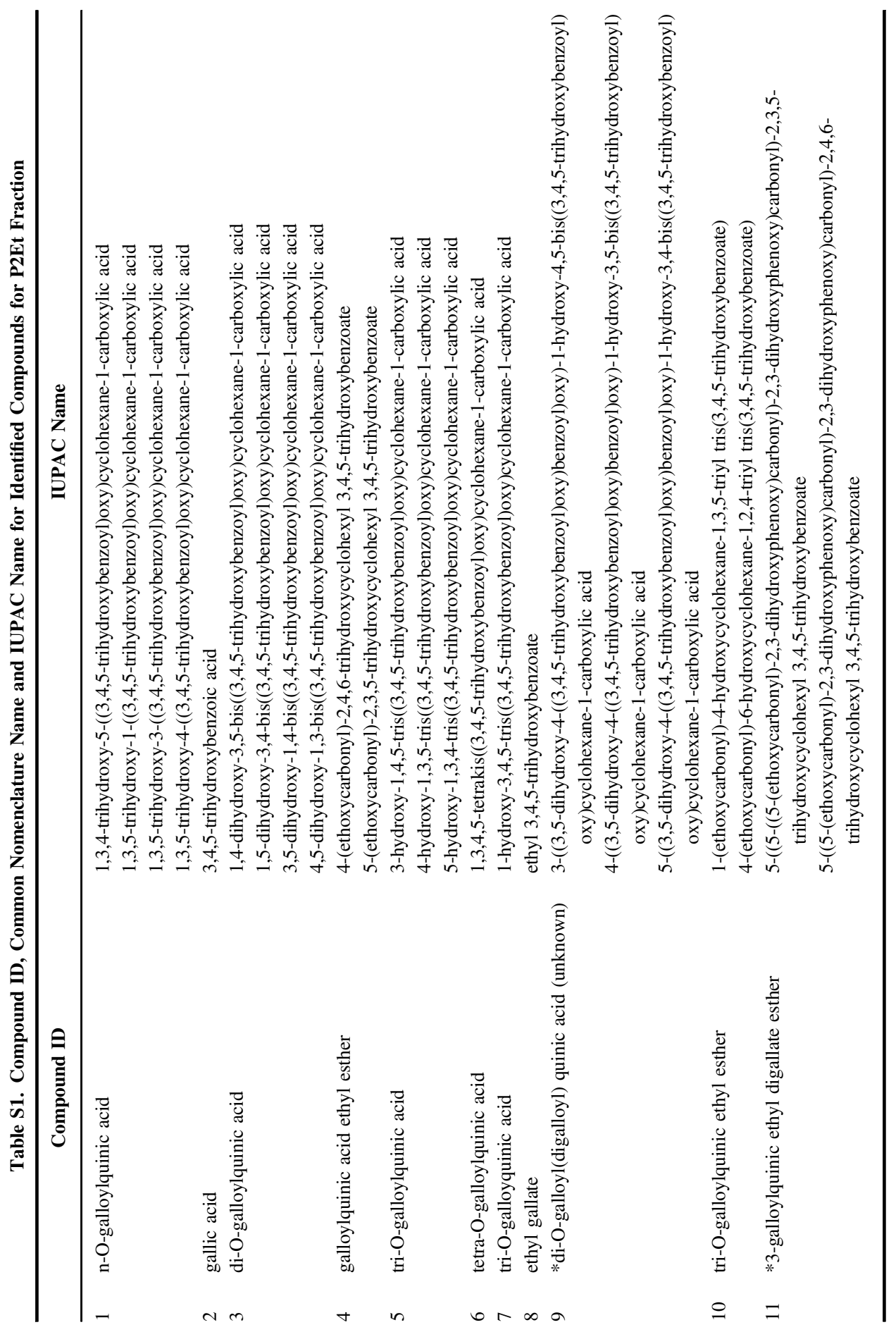



Table S2. Anti-oxidant Activity of the P2Et Extract Evaluated Using ABTS and ORAC Methods

\begin{tabular}{lcc}
\hline \multicolumn{3}{c}{ Anti-oxidant Activity ( $\boldsymbol{\mu m o l}$ TROLOX/mg) } \\
\hline & ABTS & ORAC \\
\hline P2Et extract & $11.76 \pm 0.58$ & $4.99 \pm 0.55$ \\
Ethyl gallate & $11.37 \pm 0.21$ & $4.67 \pm 0.82$ \\
Gallic acid & $16.62 \pm 4.55$ & $9.66 \pm 0.19$ \\
\hline Note:
\end{tabular}

Table S3. Synergy of Gallic Acid and Ethyl Gallate with Doxorubicin

\begin{tabular}{|c|c|c|c|c|c|}
\hline \multirow[b]{2}{*}{ Gallic acid( + Dox $)$} & & \multicolumn{2}{|c|}{ DRI } & \multirow[b]{2}{*}{ CI } & \multirow[b]{2}{*}{ Interpretation } \\
\hline & & $\mathrm{IC}_{50}$ & $0.2 \times \mathrm{IC}_{50}$ & & \\
\hline \multirow[t]{2}{*}{ MES-SA Dx5 } & $\mathbf{P}-\mathbf{g p} \mathbf{p}^{+}$ & 0.72 & 0.89 & 1.24 & - \\
\hline & P-gp ${ }^{-}$ & 0.9 & 1.3 & 1.06 & \pm \\
\hline \multirow[t]{2}{*}{ K562 } & P-gp ${ }^{+}$ & $\mathrm{N} / \mathrm{C}$ & 0.874 & 1.34 & -- \\
\hline & P-gp ${ }^{-}$ & 0.672 & 1.72 & 0.78 & ++ \\
\hline \multirow[t]{2}{*}{$4 \mathrm{~T} 1$} & WT & 1.205 & 1.182 & 1.04 & \pm \\
\hline & H17 & 0.986 & 1.23 & 1.01 & \pm \\
\hline TS/A & & 0.988 & 1.01 & 1.18 & - \\
\hline Ethyl gallate $(+$ Dox $)$ & & $\mathrm{IC}_{50}$ & $0.2 \times \mathrm{IC}_{50}$ & & \\
\hline \multirow[t]{2}{*}{ MES-SA Dx5 } & P-gp ${ }^{+}$ & 0.89 & 0.95 & 1.64 & --- \\
\hline & P-gp ${ }^{-}$ & 1.04 & 0.8 & 1.56 & --- \\
\hline \multirow[t]{2}{*}{ K562 } & $\mathbf{P}-\mathbf{g p}{ }^{+}$ & $\mathrm{N} / \mathrm{C}$ & $\mathrm{N} / \mathrm{C}$ & $\mathrm{N} / \mathrm{C}$ & $\mathrm{N} / \mathrm{C}$ \\
\hline & P-gp ${ }^{-}$ & 8.33 & 1.72 & 0.32 & +++ \\
\hline \multirow[t]{2}{*}{$4 \mathrm{T1}$} & WT & $\mathrm{N} / \mathrm{C}$ & 2.933 & 0.541 & ++ \\
\hline & H17 & 1.45 & 1.20 & 1.03 & \pm \\
\hline TS/A & & 0.986 & 1.00 & 1.15 & - \\
\hline
\end{tabular}

Note: Drug reduction index (DRI) and combination index (CI) after sensitization with $\mathrm{P} 2 \mathrm{Et}$ at concentrations equivalent to $\mathrm{IC}_{50}$ and $0.2 \times \mathrm{IC}_{50}$ for $3 \mathrm{~h}$ and doxorubicin for $48 \mathrm{~h}$ in different cell lines. Results are interpreted as Chou (2006). $\mathrm{CI}<0.1$ means very strong synergism $(+++++), 0.1-0.3$ strong synergism $(++++), 0.3-0.7$ synergism $(+++), 0.7-0.85$ moderate synergism $(++)$, $0.85-0.9$ slight synergism $(+), 0.9-1.10$ nearly additivity $( \pm), 1.10-1.20$ slight antagonism (-), 1.20-1.45 moderate antagonism (--), 1.45-3.3 antagonism $(---), 3.3-10$ strong antagonism $(----)$, and $>10$ very strong antagonism $(-----), \mathrm{N} / \mathrm{C}$ : not calculated. 